Article

\title{
Cultural Heritage Appraisal by Visitors to Global Cities: The Use of Social Media and Urban Analytics in Urban Buzz Research
}

\author{
Karima Kourtit ${ }^{1,2,3,4,5,6} \oplus$, Peter Nijkamp ${ }^{1,4,5,6, *}$ and João Romão ${ }^{6,7}$ \\ 1 Smart Cities \& Data Analytics Lab, JADS (Jheronimus Academy of Data Science), \\ 5211 's-Hertogenbosch, The Netherlands; k.kourtit@jads.nl or k_kourtit@hotmail.com \\ 2 Department of Social and Economic Geography, Uppsala University, 75120 Uppsala, Sweden \\ 3 Centre for the Future of Places (CFP), KTH Royal Institute of Technology, 11428 Stockholm, Sweden \\ 4 Institute of Socio-Economic Geography and Spatial Management, Adam Mickiewicz University, \\ 61712 Poznan, Poland \\ 5 Center for European Studies, Alexandru Ioan Cuza University, 700506 Iasi, Romania \\ 6 School of Architecture, Planning and Design, Mohammed VI Polytechnic University, \\ Ben Guerir 43150, Morocco; joao_romao@me.com \\ 7 Centre for Advanced Studies in Management and Economics (CEFAGE - UALG), University of Algarve, \\ 8005-139 Faro, Portugal \\ * Correspondence: p.nijkamp@jads.nl or pnijkamp@hotmail.com
}

Received: 6 March 2019; Accepted: 23 May 2019; Published: 24 June 2019

check for updates

\begin{abstract}
An attractive cultural heritage is an important magnet for visitors to many cities nowadays. The present paper aims to trace the constituents of the destination attractiveness of 40 global cities from the perspective of historical-cultural amenities, based on a merger of extensive systematic databases on these cities. The concept of cultural heritage buzz is introduced to highlight: (i) the importance of a varied collection of urban cultural amenities; (ii) the influence of urban cultural magnetism on foreign visitors, residents and artists; and (iii) the appreciation for a large set of local historical-cultural amenities by travelers collected from a systematic big data set (emerging from the global TripAdvisor platform). A multivariate and econometric analysis is undertaken to validate and test the quantitative picture of the above conceptual framework, with a view to assess the significance of historical-cultural assets and socio-cultural diversity in large urban agglomerations in the world as attraction factors for visitors. The results confirm our proposition on the significance of urban cultural heritage as a gravity factor for destination choices in international tourism in relation to a high appreciation for historical-cultural amenities.
\end{abstract}

Keywords: cultural heritage; global cities; attractiveness; historical-cultural amenities; language diversity; cultural heritage buzz; foreign visitors; residents; artists; TripAdvisor; fractionalization index

\section{Tourism and Cultural Heritage Buzz}

Tourism - as part of a broader leisure economy — is nowadays for many countries and regions the most important export industry. Despite the economic recession phenomena over the past decade, international tourism has globally shown a steady through somewhat lagged growth $[1,2]$. The global tourism industry is nowadays responsible for revenues amounting to over $\$ 3.2$ trillion annually. In this context, cultural tourism comprises a significant and growing share of the international tourism sector. It seems plausible that this leisure-instigated trend will continue in the decades to come, so that tourism will remain an important source of revenues for local or regional economies. Clearly, there is a need to assess the socio-economic importance of various categories of tourism for local, regional or national 
economies [3-5]. Likewise, it is necessary to identify in a transparent and measurable way the multiple determinants of the attractiveness of tourism destination places. There is a wealth of literature on destination competitiveness and attractiveness of tourist places. In the present study, the focus is on the tourism magnet function of cultural heritage in large cities.

Tourism is in general a multi-faceted industry with a heterogeneous set of visitors' aims to travel abroad, such as sun, sea, nature, health, VFR (visits to friends and relatives), entertainment, arts and culture. These distinct categories are not mutually exclusive, but do often overlap. Tourism is usually a multi-purpose trip. An important constituent of tourism is formed by cultural tourism. In the literature, there is no conclusive definition of cultural tourism, but rather an appropriate one is given by [6]: "Visits by persons from outside the host community motivated wholly or in part by interest in the historical, artistic, scientific or lifestyle/heritage of a community, region or institution". The majority of tourists visiting another country or city engage, in one way or another, also in cultural interests, visits or activities, such as arts, archaeological sites, museums, religious places, monuments, festivals, gastronomy, architecture, historic-cultural heritage, local habits, etc. It is evident that cultural tourism leaves a cognitive, historical-cultural footprint behind in the mind of visitors, through a memorable experience on the sense of place created by cultural engagement, socio-cultural contacts with locals or natives, familiarity with local conditions, and historical and site-specific interests and impressions.

Cultural tourism has prompted a wealth of research in recent years. A broad collection of both conceptual and empirical contributions to cultural tourism and its socio-economic significance for local development can be found, inter alia, in $[7,8]$. There is also a plethora of studies on the motivations, preferences and satisfaction factors of visitors in relation to cultural destinations and sites (see e.g., [9-14]. In particular, [15-17]) or provide empirical evidence on the different behaviors and satisfaction of tourists regarding local cultural amenities or historical heritage according to their own characteristics and cultural backgrounds.

Cultural tourism generates also many economic revenues for the destination place. It is clearly a source of local employment, new local business, tax revenues from sales, appreciation for and use of local cultural amenities, and improvement of quality of life through local public investments. Studies on the assessment of economic benefits of maintenance and investments in cultural heritage can be found inter alia in [18-24].

It is noteworthy that cultural amenities tend to create also vibrancy and lively neighborhoods in cities, in particular, as such goods are often accompanied by a great cultural-ethnic diversity (see also [25]. Such historical-cultural resources are often concentrated in lively and dynamic urban districts and may contribute significantly to urban vitality and sustainability $[26,27]$. Thus, historical-cultural amenities may become a novel and contemporaneous source of social and economic vibrancy of urban agglomerations or specific urban districts, such as Quartier Latin in Paris, or Soho in London [28].

The notion of cultural heritage buzz will be employed to describe a spatial concentration of vibrancy, vitality and sustainability in urban areas or districts (buzz) — based on indigenous and attractive place-based assets or landmarks in such areas. Such a magnet originates from the local and abundant presence of historical-cultural heritage amenities (such as museums, cathedrals, historical sites, historical-cultural ambiance, etc.). These amenities may create-in combination with local economies of people's density, social-cognitive proximity, international social liaisons, and ethnic-cultural diversity-a seedbed for the visitors' appreciation of original and authentic lifestyles, behaviors, landmarks, townscapes, and social contacts. This phenomenon is sometimes apparent in the form of unconventional socio-cultural heterotopias $[5,25,29]$. A heterotopia is a place where individuals (residents and/or visitors) can adopt a new imagination and are exposed to a behavior or lifestyle that is different from the average or daily lifestyle $[29,30]$. A heterotopia may incorporate unique attractiveness features that act as magnets for foreign visitors, and is a manifestation of the experience economy. An illustrative case study on socio-cultural heterotopias related to the Red Light District and the Coffee Shop District in Amsterdam can be found in [29]. 
Such diversity-rich urban districts lead to attractive hotspots of visitors to a culture-rich locality, named here cultural heritage buzz. This spatial diversification on both the consumer and the producer side prompts pluriform and diverse spiky urban landscapes of flows of visitors in cities [25,31]. This phenomenon nowadays is strongly reinforced by the use of digital location-sharing services (such as Facebook, Twitter, Foursquare) that stimulate social, spatial and cultural proximity linkages and mutually adaptive behaviors [32-34]. An intriguing question now is the extent to which urban cultural heritage buzz areas are a major attraction pole for visitors, and if so, why.

The present paper aims to explore the attractiveness factors, and the impacts of urban cultural amenities in relation to value patterns of visitors/artists/residents and appreciation scores of international travelers in 40 major world cities, based on a rich data set on amenities and attractions of these cities. This study is based on a joint examination of extensive statistical data collected on both relevant indicators and actors' value systems for 40 large cities of the world and individual big data of travelers' appreciations collected from the information base of the world-wide TripAdvisor platform.

The paper is organized as follows. After this introductory section, Section 2 offers a general sketch of the significance of digital information in the tourism sector, since social media information is a foundation stone for this study. There will be particular emphasis on digital information from the TripAdvisor platform website. In Section 3 the database is discussed on relevant historical-cultural heritage indicators and related actor value systems, as well as detailed appreciation scores, from the TripAdvisor platform, by a great diversity of visitors to the 40 cities concerned. Next, Section 4 is devoted to a conceptual and operational underpinning of the regression model developed and used to test relevant hypotheses on the determinants of cultural heritage buzz in large cities. After an interpretation of these results, the paper will be concluded with some policy implications and general lessons.

\section{Digital Information and Tourism}

The tourism sector is rather well documented in statistical data bases, e.g., in the TSA (Tourism Satellite Accounts). A centerpiece of empirical information on visitors' appraisal of historical-cultural amenities in world cities originates from digital social media. Over the past decades, information and communications technology (ICT) has exerted a decisive influence on the tourism industry. Both the supply side (electronic booking systems, internet information provision, travel logistics, hospitality management etc.) and the demand side (online information acquisition on tourist sites, travel behavior, interactive social media use, etc.) have shown drastic changes in priority choices, strategies and behaviors affecting the tourist sector's development. This manifests itself in, e.g., co-creation of destinations, by combining the supply of tourism services with the preferences of tourists via their interactions through digital technologies [35]. A related trend is the impact of travelers shaping the image of destinations, through the multimedia contents they can easily produce and spread in social networks [36].

The great potential of digital technology as a tool of mass collaboration-as defined by [25] -leads far-reaching footprints in tourist behavior in terms of both strategic decisions and day-to-day choices (see e.g., for a broad overview [37]. The extensive acceptance of ICT in tourism has also been stimulated by the prevailing trend towards intelligent or smart city policies and strategies based on digital technology and social media use [38-52].

In recent years, the rapid emergence of various digital technology applications in the tourist sector, such as the use of smart phone devices, is noteworthy. Digital information (e.g., for trip bookings, travel decisions, tourist site evaluations, etc.) has become a core element of modern tourism [53-56]. The combination of internet travel information with real-time information through smart phones has prompted a wide range of interesting applications that go far beyond advanced online booking systems or trip decisions. In the past years, novel cyber applications have also been developed in consumer evaluation systems of tourist sites and destinations, and this has prompted original and novel forms of social science research in the tourist sector [57-63]. 
In the digital world, the use of digital social media in tourism behaviors has seen rapid progress. An analysis of social messages (e.g., Facebook, Instagram, Foursquare, Twitter etc.) has brought to light interesting social-geographic patterns of tourist behavior in cities leading, for instance, to urban language maps of visitors, space-time concentration of visitors in specific urban sites, density maps of different language groups in touristic sites, or novel insights into the satisfaction levels of different tourist groups in different sites or destinations (using, for instance, principles from geographic happiness or mood research; [64].

It is noteworthy that also various websites do exist which act as booking or information sources for tourists (such as Brooking.com, or Trivago). A rather popular one is TripAdvisor which serves as a platform for information advisory on trips, in particular tourist destinations. TripAdvisor has a rich and partly publicly accessible database on tourist attractions, though not exclusively or specifically on cultural touristic sites, destinations or landmarks. However, it has very useful and accessible information that can be distilled from this systematically designed, open information platform, which is a rich source of micro information.

A concise description of TripAdvisor, which is a most prominent information source for visitors, will be used in our empirical research on an operational data base. TripAdvisor, created in the US in the year 2000, acts as a non-booking agent in a user-generated information advisory platform with systematic information on a wide array of items making up for the attractiveness of tourist destinations [see 38]. The TripAdvisor website contains various categories of travelers' views and recommendations and may be regarded as a valuable online source of reference for travelers, based on impartial records, experiences and viewpoints of actual previous visitors to a site. It contains rankings and league tables of tourist items (e.g., hotels, restaurants, museums) based on on-line perceptions, experiences and impressions expressed by consumers. The internet-mediated information platform contains often thousands of evaluation statements by travelers and spurs trust based on the truth of the masses principle [65].

The TripAdvisor on-line system is an example of a social-science based big data system and has recently prompted user interest and original research in various fields. Examples are:

- Visitors' reviews of the quality of hospitality, in particular hotels. Empirical studies using TripAdvisor information can be found inter alia in $[66,67]$.

- Satisfaction and attractiveness scales of various touristic attractions using the 5-point numerical scale used in the TripAdvisor assessment system. Various studies have been undertaken in the past years, amongst others by $[14,28,36,62,68,69]$.

- Credibility of and trust in TripAdvisor information by travelers. Empirical research on this issue can be found inter alia in $[70,71]$.

- Content analysis of, e.g., emotional expressions, language use and language proficiency, image detection, cultural style and so forth. Empirical studies can be found in, amongst others, [14,62,72-74].

- Assessment of destination image and cultural heritage based on quantitative or qualitative content analysis or perception analysis. Only a few studies in this field have been carried out, amongst others, by [74].

From the above (incomplete) overview of TripAdvisor applications, it is clear that this platform opens a rich variety of potential applications on hospitality and tourism research. Clearly, the current research using this rich information system is still in its infancy. The same holds for other social media sources of platform information on individual travel behavior, preferences and perceptions. The TripAdvisor database is nowadays increasingly used in tourism and marketing studies. The open access nature of the platform makes it suitable as a public database for scientific research. Next to the studies mentioned in the text, we refer here also to studies by [52,75-80], undertaken by using the Tripadvisor platform data base. This micro-based type of information will now be combined in this study with meso-oriented data on a wealth of attractiveness and performance factors of many global cities (see Section 3). In this empirical application, a specific open-access part of the TripAdvisor 
platform information base, nl., will be employed and the review of visitors to various world cities (40 in total) in regard to their appreciation of the presence of historical-cultural heritage in these cities. The nature of the integrated data base for this study will be highlighted in Section 3.

\section{Methodology and Database}

\subsection{Research Framework}

The concept of cultural heritage buzz is used in our study to frame the central research on the magnet function of historical-cultural heritage. The information base for our empirical study originates from both verified statistical information and individual appreciation data from social media. Both multivariate methods and regression models will be used to map out this complex appreciation system and to identify empirically prominent explanatory factors. The conceptual model of this study is presented in Figure 1. The description of the measurable variables/indicators in this figure will be provided later in the operational model(s) to be estimated. The framing of our analysis in Figure 1 is based on the hypothesis that cultural heritage indicators and the appreciation of this heritage by various actors induce a cultural magnet function of the cities concerned, which in combination with social-cultural diversity in these localities, creates a cultural heritage buzz which satisfies the needs of visitors (in terms of visitors' appreciations and visits). Thus, the presence and/or supply of heterogeneous cultural amenities is supposed to prompt the visitors' volumes and appreciations for these urban goods, in which visitor-specific characteristics may act as moderator variables.

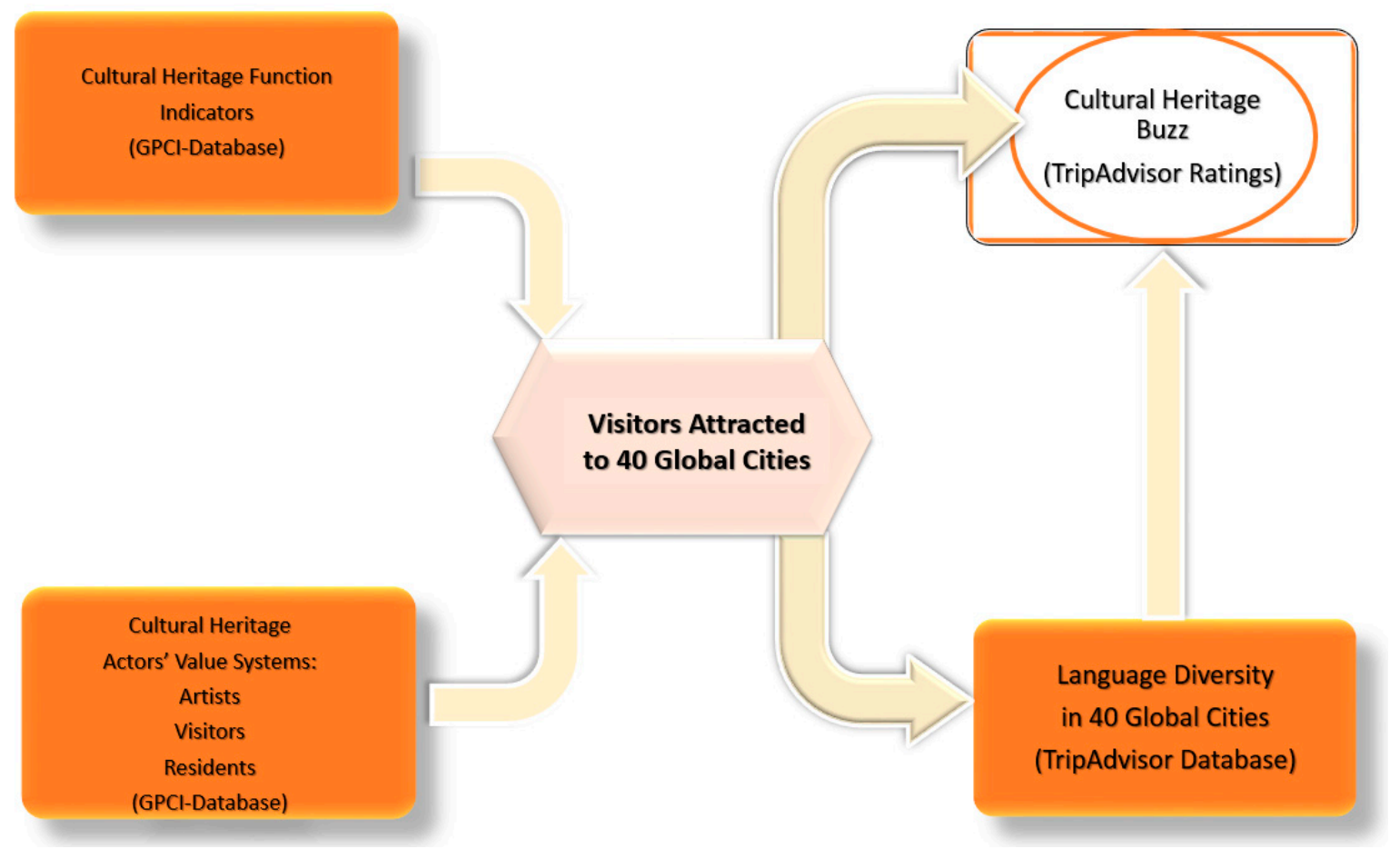

Figure 1. The conceptual architecture of the nexus of cultural heritage, stakeholders' value systems, and visitors' appreciations.

The conceptual framework from Figure 1 will be tested, with the aim to explain the users' satisfaction with cultural goods in a city from a series of plausible background conditions articulated in the literature overview in this study. The database used for our empirical application on the identification of the determinants of cultural heritage buzz in global cities comprises two types of data systems:

- Extensive data on a great variety of quantitative performance and attractiveness information on 40 world cities. These data—called the Global Power City Index (GPCI)—are collected on an 
annual basis (since 2008) by the Institute for Urban Strategies, the Mori Memorial Foundation (Tokyo) (see Section 3.2).

- Massive volumes of data collected from the open TripAdvisor platform. These data reflects the individual and collective appreciation on a great variety of cultural heritage attractions by thousands of visitors-differentiated according to socio-demographic and other features. This is a world-wide information system, from which culture-relevant items and indicators related to the 40 global cities in the GPCI sample have been obtained (see Section 3.3).

A brief account of both data systems in Sections 3.2 and 3.3, respectively is provided.

\subsection{The Global Power City Index (GPCI) Database}

Since its inception in the year 2008, the Institute for Urban Strategies (Tokyo) has annually produced a Yearbook containing a rich data set on 40 world cities, comprising not only of big metropolitan areas (e.g., New York, London, Paris, Tokyo), but also smaller agglomerations (e.g., Copenhagen, Geneva). Given the emerging competition among most large cities in the world (e.g., on attracting headquarters of multinationals, large public agencies, financial institutions, etc.), there is an urgent need for reliable, comparable and quantitative performance and attractiveness indicators on these cities. This need is also in line with the current trend to employ KPIs (Key Performance Indicators) in public and private strategic decisions. By delivering each year an extensive annual GPCI study report, also a trend analysis can be undertaken, for instance, as the basis for a SWOT analysis or a benchmarking experiment by means of the GPCI database.

The GPCI database contains for each of the 40 cities under consideration 2 main classes of extensive information, viz. (i) a function-specific database and (ii) an actor-specific database. A concise description of these two information systems is provided.

(i) Function-Specific Database

The function-specific database comprises 6 main components, each subdivided into various unambiguously measured and systematically defined performance and attractiveness indicators (approximately 70, in total) on all global cities in the GPCI sample. These indicators include:

- Economy

- Research and Development

- Cultural Interaction

- Livability

- Environment

- Accessibility

The annual GPCI reports provide a wealth of statistical information on many key performance indicators on all global cities in the sample of 40 .

(ii) Actor-Specific Database

The actor-specific database maps out the value systems (in particular, regarding preferences/perceptions) of 5 classes of stakeholders (actors) involved with the local and international functioning of the global cities concerned. These data are based on extensive and regular inquiries among the stakeholders in all these cities. The relevant classes of actors in the GPCI database are:

- Managers

- Researchers

- Artists

- Visitors

- $\quad$ Residents 
The annual GPCI reports provide extremely interesting and relevant information (for both policy-makers and researchers) on the value systems and judgements of these actors regarding the items or achievement indicators of the cities at hand. The major strengths and advantages of the GPCI data system are the provision of:

- A systematic comparison of about 40 major cities in our world;

- A multidimensional criteria set for quantitative benchmarking and rank orders of cities;

- An empirically verified and testable collection of comparative quantitative data on many important aspects of modern cities;

- An involvement of many stakeholders in different—local and global—sectors of contemporaneous city life;

- A multi-annual updating of the information, so that a unique data set-up-to-date-is obtained as a basis for urban monitoring. This continuity in information gathering is a major attraction and strong asset of GPCI.

From the above described GPCI database, various items will be selected that are relevant in the context of this study on the significance of urban historical-cultural heritage elements for the presence of urban cultural buzz (see Section 4). The hypothesis is that a distinct set of urban performance and attractiveness indicators from the GPCI database (in particular, data on museums, historical sites, monuments etc.) will exert a positive influence on the cultural heritage buzz. This proposition calls for an empirical test to be carried out in the remaining part of the paper.

\subsection{The TripAdvisor Database}

The next part of our database comprises a wealth of individual-based big data distilled from the TripAdvisor platform. These 'big data' are not only large in volume, but also heterogeneous in scope. As mentioned above, the TripAdvisor database is a very rich and detailed data system on the appreciation of millions of visitors to cities all over the world. It is one of the examples of a digital big data base, comprising opinions of numerous travelers on various attractions in cities all over the world. Such opinion statements may contain appreciations of hotels or restaurants, public amenities, historical-cultural goods and assets, entertainment opportunities, or quality of life in cities, etc. Such visitors' appreciations may assume two forms:

- An expression of appreciation for an item on a Likert-scale (1 to 5).

- A qualitative statement on the traveler's like or dislike for a certain amenity, in any language.

This study has collected information from the open-access TripAdvisor database from thousands of travelers on various attraction amenities in the historical-cultural domain in all GPCI cities under investigation. More precisely, information was acquired on a numerical (1-5) scale for each of the historical-cultural amenities in the 40 global cities. This information led to a specific appreciation rating for each individual cultural amenity in the city at hand. The database contains information on the perceived value of a large set of local cultural goods, each visited by travelers in different numbers. In this way, an average cultural appreciation score per city may be computed. As the total number of reviewers was known for each cultural attraction good or asset, it was possible to calculate a Weighted Average Appreciation Index (WAAI) of all relevant cultural amenities in the city concerned. This index was calculated as an unweighted average of all individual evaluations for all relevant cultural amenities for each city. Since all appreciations are expressed on a 1-5 point scale, it is evident that $0 \leq$ WAAI $\leq 5$. In practice, it became apparent that higher appreciations (i.e., above 4 ) are more present in the TripAdvisor system than lower appreciations. This WAAI can be calculated for all 40 cities in our sample and reflects essentially the attractiveness of-or appreciation for-a city seen through the eyes of a great diversity of visitors to specific historical-cultural attractions. It may be conceived of as a proxy for cultural heritage buzz to be expected in a regression analysis and used. 
It is also interesting to note that for each historical-cultural item, socio-demographic data (e.g., family, single) and gender information on the visitors is also available, as well as information on the age cohorts and used language of the travelers concerned. Consequently, the aggregate age frequency distribution-in terms of participation by travelers in age cohorts-and the gender distribution and the language distribution are known as well. Consequently, from the TripAdvisor data system, access has been gained to a wide variety of interesting data on travelers to specific historical—cultural assets in a city that are excessively interesting for a better understanding of urban cultural buzz.

\subsection{Cultural Diversity among Visitors}

An important added value of the TripAdvisor data requires emphasis. It is, as mentioned, possible to extract from the TripAdvisor platform detailed data on the language used by the traveler for each cultural amenity. This language information-and hence, the relative frequency of the use of a given language in the TripAdvisor information platform on the expressed appreciation for various specific cultural items visited-provides a picture of the pluriform cultural-linguistic composition of all visitors and mirrors clearly the socio-cultural diversity related to urban buzz. It may be added that language diversity regarding a certain urban district may be seen as a proxy indicator for cultural diversity among visitors in an urban heterotopia, with a distinct and characteristic place identity or amenity identity. Clearly, such language information may sometimes be related to a specific country (e.g., Japanese, Finnish, Italian), but this is not always the case (e.g., English, Spanish).

This language information is thus available per cultural attraction item in each city. Given the knowledge on the relative shares of reviewers/visitors to each historical-cultural amenity, a Weighted Average Diversity Index (WADI), based on the average differences in language used by the travelers can be calculated. The sign impact of the WADI score on cultural heritage buzz (i.e., WAAI) is an empirical question and needs to be tested. It seems a plausible hypothesis that a negative impact may be present, as in international tourist visits to unknown countries, familiarity with the language used by other fellow-visitors (i.e., a low language diversity among visitors) is likely to be a positive attraction factor. This would be in line with social capital theory. Such a risk-avoiding attitude among visitors may lead to the reasonable expectation that less diversity among the visitors may increase their appreciation for the sites (and hence, the city) visited. The reverse of this phenomenon, viz. lack of mutual understanding, is sometimes called a Babylon effect. The data analytics will explain which hypothesis is empirically supported.

This TripAdvisor database will be used in our investigation on the selection of determinants of urban cultural heritage. Thus, both the urban WAAI and the urban WADI are able to provide meaningful and aggregate travelers' information for urban strategic policy regarding culture, history and architecture. This extensive amenity-specific and city-specific information will in our modelling application be combined with information from the above mentioned GPCI database (see Figure 1). Clearly, several data collection options still have to be explored in regard to smart urban goal strategies. Therefore, the above mentioned blend of two data systems may be of critical importance in this regard.

After this concise description of the database, a sketch of the architecture of our approach to be empirically tested will be provided.

\section{Modelling the Cultural Heritage Buzz of Visitors in Global Cities}

As outlined in Figure 1, the aim is to trace the determinants of cultural buzz in the city, based on a blend of information on a multiplicity of relevant indicators. A starting point will be specifying successively the ingredients of our core conceptual model sketched in Figure 1. This will then lead to an empirical test model (see Figure 2). 


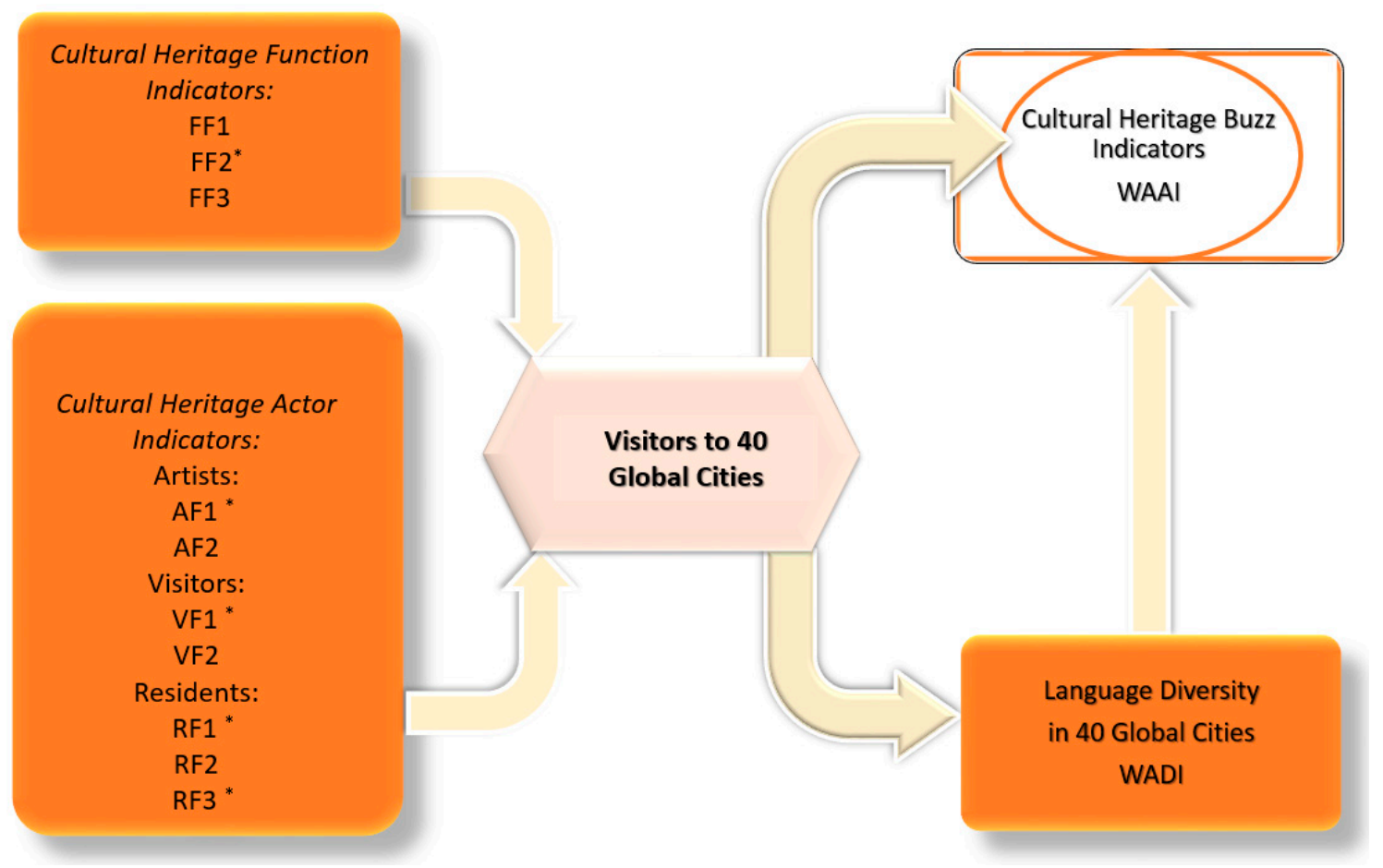

Figure 2. Operational model for estimating cultural heritage buzz. *: The items marked with an * were eliminated for statistical reasons in the final regression, as they showed a high degree of multicollinearity with other items and not contribute to a better statistical fit (see also Appendix A).

\subsection{Cultural Heritage Function Indicators}

The cultural heritage indicators represent the scores for the available amenities or performance functions on the supply side of cities included in the GPCI database, subdivided according to the 6 main indicators described in Section 3.1. A distinct set of sub-indicators, directly or indirectly related to the presence, attractiveness or use of historical-cultural amenities in the cities concerned, was selected as positive stimuli for attracting visitors/businessmen or for pleasing the residents. From the total set of GPCI function-specific sub-indicators, 26 items were selected as potentially relevant determinants of urban cultural attractiveness. It is evident that this varied set of 26 scores is too large to be used in an explanatory regression model. To reduce the size of this set and to cope with multicollinearity among these 26 sub-indicators, a principal component analysis (PCA) was used. This led to the identification of 3 independent factors which in combination represent a fairly reliable mapping of these cultural function sub-indicators across all 40 cities (see for details Appendix A, Table A1). These functional factors may roughly be interpreted as follows:

- Factor 1 (FF1): Visitors' attractiveness in relation to socio-cultural facilities, as is exemplified by sub-indicators like cultural events, creative activities, shopping, museums, theatres and concert halls, etc.

- Factor 2(FF2): Travelers' logistic conditions, reflected inter alia in taxi facilities, airport connection, etc.

- Factor 3 (FF3): Visitors' connectivity and spatial quality conditions, including inter alia urban green, heritage sites, and international connectivity, etc.

Consequently, the Cultural Heritage Indicators block in Figure 1 can be decomposed into the following functional constituents for all 40 cities: FF1, FF2, FF3. These form part of the empirical model.

\subsection{Cultural Heritage Actor Indicators}

Next, the set of actor-oriented indicators is addressed for urban historical-cultural heritage, subdivided over the stakeholder categories: artists, visitors, and residents. The total number of 
preselected sub-indicators which are assumed to have a direct or indirect relationship with urban heritage amenities is 18 . Also, in this case, the same approach is applied by using a PCA to reduce the large number of predictors to a smaller subset of uncorrelated explanatory components (to avoid multicollinearity), differentiated according to the 3 above mentioned target groups (see Appendix A, Table A2). This leads to the following findings and interpretation:

- Artists: Factor 1 (AF1): Creative ambiance, represented inter alia in cultural stimulation or art markets. Factor 2 (AF2): Ease of living, reflected in the urban environment for daily life.

- Visitors: Factor 1 (VF1): Local attractiveness, reflected in cultural interaction, wealth of amenities, and convenient access, etc. Factor 2 (VF2): Quality of travelers' facilities, such as accommodation and shopping, etc.

- Residents: Factor 1 (RF1): Local quality of life, as indicated by environment and safety in the city. Factor 2 (RF2): Public health, in terms of medical facilities, etc. Factor 3 (RF3): Consumer ease, for instance, easy access to shops, etc.

Based on the above PCA results, the Actors' Value Systems block of Figure 1 can be decomposed into 3 sub-blocks: Artists (AF1, AF2), Visitors (VF1, VF2) and Residents (RF1, RF2, RF3).

The above indicators originate all from the GPCI database, which comprises only verified statistical data. The data from the TripAdvisor platform, which contains individual value expressions, is now addressed.

\subsection{Language Diversity Indicators}

It is plausible that an appropriate supply of attractive cultural amenities in a city may act as a stimulus for heterogeneous visitors and artists, while also locals will likely enjoy these facilities. These positive urban agglomeration advantages—enjoyed by different groups of users—will probably be affected by economies related to cultural-ethnic diversity as reflected in the language used by the visitors. A tourist's experience in a heterotopian city with an unknown environment may be perceived as somewhat risky by many visitors, if there is no one to share their own language or the tourist experiences. This may imply that a high language diversity may be perceived as a barrier to the appreciation by many tourists, especially for those with a low foreign language proficiency. For several travelers, it may be much easier to go around in a city, if there is no language barrier (in other words, if there is a low language diversity). Consequently, our econometric model is tested for the presence of a Babylon effect, i.e., whether a low language diversity — caused by many foreign visitors—has a positive impact on the visitors' appreciations of a local culture or cultural site in a city.

In the TripAdvisor platform database, it is possible to identify the shares of the language by the visitors/reviewers of each individual historical-cultural amenity in the city concerned. As mentioned in Section 3.2, the WADI language diversity can be computed on the basis of the weighted average scores of language use for each historical-cultural facility in a particular city. As these shares of language use for each city have been obtained, an urban language diversity index can be calculated, based on the fractionalization index (defined and applied amongst others by [81,82]. Clearly, there are many other diversity indices [83], but the fractionalization index is straightforward and easy to interpret. It is defined as follows:

$$
\text { WADI }=1-\sum_{i=1}^{\mathrm{I}}(\text { share of language } i)^{2}
$$

The extensive language information from the big data TripAdvisor platform will now be used to calculate the value of WADI for each city under investigation (see Appendix A, Table A3). This information is used in our econometric model as a possible explanatory variable negatively impacting the travelers' appreciation for a given cultural supply in a city.

\subsection{Cultural Heritage Buzz Indicators}

Finally, an operational meaning to the cultural heritage buzz variable is provided, which is the dependent variable in our econometric model (Figure 2). As mentioned before, this variable is approximated 
by the city-specific cultural-historical attractiveness score which comprises the attractiveness scores of each individual cultural asset in the city concerned, given by the travelers to that city. This overall weighted index of cultural attractiveness-described as WAAI - depicts the cultural heritage buzz of a city, as perceived by the tourists who expressed their appreciation for each individual historical-cultural item on a Likert-scale. The selected data cover the same period as the GPCI data.

Integration of the various extensive databases described above leads to the following operational specification of a cultural heritage buzz model as a function of a multiplicity of determining factors (see Figure 2). The reduction of a wealth of diverse data to an organized set of measurable data was clearly a major challenge. The resulting regression model will next be estimated and tested empirically.

For our empirical application, several statistical pre-screens have been made to avoid multicollinearity in the database and to eliminate irrelevant variables that had no explanatory meaning. This led ultimately to the formulation and estimation of a core model based on the architecture of Figure 2, which has-for reasons of statistical significance-eliminated the following items from the two blocks on the left-hand side of this Figure: FF2, AF1, VF1, RF1 and RF3. The reason to eliminate these sub-indicators are-apart from the number of degrees of freedom in our model一the following. FF2 is difficult to justify in an explanatory model, as general logistic conditions are not necessarily related to cultural interests and subsequent ratings (apart from the statistical fact that FF2 has a high degree of multicollinearity with some other sub-indicators in this area and never offers a significant contribution). AF1 (urban ambiance for artists) appears to be highly correlated with the most prominent factor FF1 of the function-specific score (urban attractiveness) and hence does not deserve a separate explanatory position. The same holds for VF1, which can therefore also be omitted. A similar argument applies to RF1, which in addition is also correlated with AF2 in our model. Finally, RF3 does not have a direct and plausible link with the visitors' ratings for cultural amenities, and is thus left out. Thus, our core regression model (as a pooled OLS model) can formally be represented as:

$$
\mathrm{WAAI}=\mathrm{f}(\mathrm{FF} 1, \mathrm{FF} 3, \mathrm{AF} 2, \mathrm{VF} 2, \mathrm{RF} 2, \mathrm{WADI})
$$

This model was the ultimate regression model to be tested (Table 1).

Table 1. Results of regression analysis for the cultural heritage buzz model.

\begin{tabular}{cccc}
\hline & Estimated Coefficients & Std. Error & Sig. \\
\hline Dindex & $-8,698$ & 2,699 & 0,003 \\
FF1 & 3,563 & 0,745 & 0,000 \\
FF3 & 1,218 & 0,622 & 0,059 \\
AF2 & $-2,549$ & 0,938 & 0,010 \\
VF2 & 0,167 & 0,842 & 0,844 \\
RF2 & 1,840 & 0,652 & 0,008 \\
Intercept & 100,235 & 1,462 & 0,000 \\
\hline Observations & 40 & & \\
$R^{2}$ & 0,52 & & \\
Method & OLS & & \\
\hline
\end{tabular}

The regression results of the econometric model emerging from Figure 2 are rather satisfactory (see Table 1). It appears that from the set of function-specific urban explanatory determinants, the attractiveness features of a culture-rich city (FF1) increase significantly the appreciation by travelers, as might theoretically be expected. Next, the accessibility and local environmental quality factor (FF3) appears to certainly make a difference for the visitors to the city concerned which also confirms our prior expectations.

In the case of artists, it appears that the ease of urban living seen from the perspective of artists (AF2) does not have a clearly positive impact on the travelers' rating for cultural amenities. This finding is not entirely unrealistic, as the ease of living will probably not be a main reason for artists to move to 
a given cultural destination. For the category of cultural visitors, the presence of expensive high-class hotels and shopping facilities (VF2) does not offer any significant explanation, which seems to be a plausible finding for this special category. In addition, these facilities appear to be lowly-ranked in the TripAdvisor platform database. Finally, for the third group of actors (the residents), public health in the city (RF2) appears to be an important significant local attraction factor, in contrast to visitors or artists.

Our overall findings on the regression results based on the GPCI data system lead to conclusions that largely confirm our prior hypotheses and may be regarded as plausible outcomes. Consequently, the propositions formulated in this study appear to stand empirical testing.

Furthermore, it is interesting to examine the impact of language diversity among travelers on their overall appreciation regarding cultural amenities and urban ambiance in the city, as expressed in the TripAdvisor data system (WADI). The results are noteworthy and confirm our hypotheses that there is a significant negative impact of language diversity among travelers on the attractiveness scores for cultural facilities or ambiance in a city. In other words, it is plausible that a particular urban social externality, viz. high language diversity among visitors, will reduce-as a result of the Babylon effect-the appreciation for cultural heritage buzz sites by visitors to a city.

It is thus concluded that the overall results of our cultural heritage buzz model are satisfactory and in agreement with plausible prior expectations on cultural tourism. To test the robustness of our regression analysis, the amended specifications were experimented by trying different combinations of less significant or satisfactory explanatory factors, for instance, by including FF2, AF1, or RF3 (separately or in combination). The inclusion of these variables did not increase the explanatory power of the model concerned, so that a conclusion was drawn that the core model based on Figure 2 is rather robust and consistent with our prespecified conceptual expectations. Thus, the TripAdvisor data (both the cultural heritage buzz data and the language diversity data) provide a novel ingredient for understanding the appreciations of cultural tourists in global cities.

\subsection{Further Empirical Interpretation}

Finally, it should be noted that the GPCI database which was used in the previous regression model only refers to the year 2015. This database is however, much richer, and covers many years. It would, therefore, be interesting to experiment with a time-varying database. This led to the decision to consider 4 subsequent years of data coverage, i.e., 2012-2015. This would make our econometric model clearly a panel data model, in which both function-specific and actor-specific data over a 4-year period would be incorporated. However, there is a serious limitation in this case, as the data collected thus far from the TripAdvisor platform system only covers the year 2015. Of course, this database could in principle be extended, but this would require a major time effort. Consequently, what could be done as a preliminary experiment at this stage, is to estimate a panel model based on a 4-year time period in which only the GPCI data, as specified in the two left-hand blocks of Figure 2, are included, while the WAAI and WADI parts would have to be left out. This would mean that the dependent variable would have to be a different one, viz. the number of visitors, to be explained by the specific cultural-heritage indicators from the GPCI database (after a transformation into the factors FF, AF, VF and RF). This leads thus to a simplified truncated model for identifying the determinants of urban cultural attractiveness, based on general tourist visits. The model results are given in Appendix A, Table A4.

The regression outcomes from Table A4 (see Appendix A), based on a truncated model, are on the other hand richer in scope, as this is a panel model. It should be emphasized that-in contrast to the cultural heritage buzz variable in our original core model-here only the number of foreign visitors is considered. For the remaining part, the structure of the model is identical to our core model, as far as the inclusion of GPCI-based factors is concerned. Clearly, a direct comparison of model results is not realistic.

The results support that the overall panel model is significant, be it with a lower R-square. In terms of function-oriented indicators, both FF1 and FF3 appear to offer a significant explanation, which is in 
agreement with the sign impact of these factors in Table 1. Regarding the actor-specific indicators, AF2, VF2 and RF2 are all significant. Clearly, there are some manifest differences here, as either the signs (AF2, RF2) or the level of significance (VF2) are different. To understand these differences, it is important to mention that the dependent variable data does not reflect the detailed appreciation scores of visitors to the cultural amenities in the city concerned, but only the absolute volumes of general visitors to a city in regard to the supply of historical-cultural assets (functions) and perceived importance of general urban functions by the three classes of stakeholders. Consequently, these findings have to be interpreted with great caution and are by no means suitable for a direct comparison with the findings of our core model. However, a key finding here is again that attractiveness of high-quality socio-cultural amenities, good transport connections and a satisfactory quality of life in large cities are a since qua non for a high interest of tourists in these cities.

\section{Conclusions and Lessons}

In this contribution, three interconnected research questions have been addressed:

- What is the influence of a variety of historical-cultural assets (functions) in a city on the traveler's appreciation of a city?

- Does the presence of specific categories of actors' value systems regarding urban cultural functions act as a magnet for the overall attractiveness of a city?

- Does a high language diversity among visitors (a Babylon effect) impact negatively the appreciation of cultural sites or amenities by foreign tourists?

Our regression estimations, based on systematically collected and organized databases on 40 global cities (GPCI) and on travelers' opinions on historical-cultural attractiveness of these cities (TripAdvisor), confirm the existence of the effects incorporated in the three above mentioned research issues. Although in very few cases, the statistical significance or the sign has to be interpreted with some caution.

Our results show clearly the importance of local amenities for tourism attractiveness (as expressed inter alia by the vector FF3), suggesting that a balanced planning of urban facilities, infrastructures and urban landscapes ('ambiance') is needed in order to enhance both the wellbeing of local residents and the urban magnetism for visitors, taking into consideration that an extensive usage of public urban space by tourists may potentially create crowding problems of congestion or degradation [84]. Our results also show that the enjoyment of general urban amenities by tourists tends to increase their satisfaction with the cultural elements of the cities concerned, suggesting that tourist satisfaction depends on the cumulative effects caused by the different components of the experience of each tourist $[65,85]$. Urban landscapes and cultural-historical amenities in a city are a closely interlinked phenomena. This suggests that the management of cultural assets for tourism purposes should be coordinated with other complementary elements of the visit related to the urban image and dynamics (public spaces, mobility, etc.).

Another important finding of our analysis is that, although it was possible to identify a significant contribution of cultural and heritage assets to the attractiveness perceptions of tourists in contemporary global cities, this is not necessarily or unambiguously related to the local dynamics of artists' cultural production (see factors $\mathrm{AF} 1$ and AF2). If cultural assets only contribute to tourism attractiveness through their commodification and integration into appropriate tourism products and services, attention is needed for other forms of cultural production and dynamics in global cities, so that favorable conditions for their development can be ensured in tandem with the current tourism demand. It should be emphasized that the study's aim is not to provide a new ranking of cultural functions of cities, but to analyze whether the visitors' perception of cultural attractiveness is causally linked to cultural profiles of these cities and other moderator variables. This is confirmed in our study.

Clearly, our study prompts interesting methodological issues related to the design of the model (which had to respect the availability of a heterogeneous set of multiple databases) and the merger of 
various data sources (ranging from meso databases or urban functions/actors to micro-based data on individual expressions of appreciation by visitors to cultural resources in the cities concerned). It is obvious that a situation of rather abundant information on individual cultural items in a city may open up several ways for new research options and directions, but also poses challenging questions on the consistent linkage of such data in a unifying research framework.

Our findings confirm, to a large extent, our prior assumptions on the expected sign of the influence of relevant moderator variables. Thus, the model is supported by statistical reliability tests and economic plausibility arguments.

It should be added that there is still a vast research area ahead. For example, the impact of gender and age on the appreciation scores of travelers or the influence of the seasonality patterns of visitors on the attractiveness of historical-cultural amenities, as perceived by them. TripAdvisor appears to have many more and under-investigated data, so that data mining will be an important challenge in future research. Content analysis, mood analysis and other new methodologies developed recently in quantitative social science research may lead to new directions in tourism research.

An important research question to be further explored in the future is whether a high attractiveness of the cultural amenities in a city will automatically lead to a higher volume of visitors, or whether complementary policy measures, such as dedicated marketing efforts, interactive communication platforms (Facebooks, Twitter, TripAdvisor, etc.), or online information on available cultural assets in the city concerned would be needed.

A related question to be further examined is whether the establishment of a distinct cultural profile of the city concerned would be instrumental in enhancing the perceived urban attractiveness by visitors, as part of a broader analysis of destination competitiveness. An example can be found in Europe, with its established and recognized policy system of an annually rotating Cultural Capital of Europe, which no doubt increases the specific cultural appeal of a city. Such a system may also be relevant and effective for urban cultural image building and urban landscape planning, which may support and stimulate cultural tourism. Thus, in a broader context, the analysis provided in the present study may also be instrumental in city marketing.

Author Contributions: Although this article is a joint responsibility of all three authors, the following global division of tasks and works of the authors concerned may be outlined. The literature overview was a common activity. K.K. and P.N. share largely the responsibility for the research design and conceptualization of the paper, as well as for the revisions in the paper during the review stage. The data collection was mainly done by K.K. The data analytics part was jointly undertaken by K.K. and J.R., while the conclusions were predominantly formulated by K.K. and P.N.

Funding: This research has received no external funding.

Acknowledgments: The authors wish to thank Jamie Chen for her invaluable assistance in collecting and computing the TripAdvisor data.

Conflicts of Interest: The authors declare no conflicts of interest. 


\section{Appendix A Statistical Data Base and Results}

Table A1. Results of Principal Component Analysis (PCA) for Function-Specific GPCI Data.

\begin{tabular}{|c|c|c|c|c|}
\hline Type & Factors & Functional Variables & $\begin{array}{c}\text { KMO and } \\
\text { Bartlett's Test }\end{array}$ & $\begin{array}{l}\text { Factor } \\
\text { Loadings }\end{array}$ \\
\hline \multirow{27}{*}{ 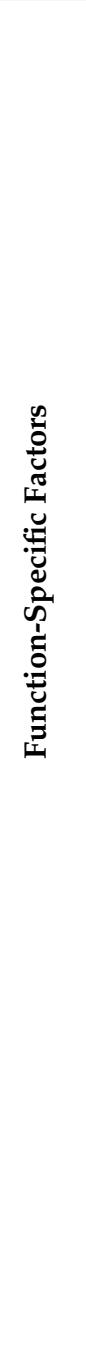 } & \multirow{19}{*}{ FF1 } & & $0,803(0,00)$ & \\
\hline & & $\begin{array}{l}\text { Number of Large World-Class Cultural Events } \\
\text { Held }\end{array}$ & & 0.795 \\
\hline & & Readiness for Accepting Foreign Researchers & & 0.777 \\
\hline & & Level of Satisfaction for Shopping & & 0.764 \\
\hline & & Environment of Creative Activities & & 0.763 \\
\hline & & World's Top 200 Universities & & 0.758 \\
\hline & & Variety of Retail Shops & & 0.746 \\
\hline & & Number of Museums & & 0.743 \\
\hline & & Level of Satisfaction for Dining & & 0.686 \\
\hline & & Research and Development Expenditure & & 0.678 \\
\hline & & $\begin{array}{l}\text { Level of Satisfaction of Employees for their } \\
\text { Lives }\end{array}$ & & 0.645 \\
\hline & & $\begin{array}{l}\text { Opportunities of Cultural, Historical and } \\
\text { Traditional Interaction }\end{array}$ & & 0.635 \\
\hline & & Number of Theaters and Concert Halls & & 0.621 \\
\hline & & Convenience of Commuting & & 0.607 \\
\hline & & Variety of Restaurant & & 0.567 \\
\hline & & Number of Hotels & & 0.522 \\
\hline & & GDP per Capita (log) & & 0.588 \\
\hline & & Price level & & 0.473 \\
\hline & & $\begin{array}{l}\text { Number of Registered Industrial Property } \\
\text { Rights (Patents) }\end{array}$ & & 0.395 \\
\hline & \multirow[t]{3}{*}{ FF2 } & Taxi Fare & & 0.724 \\
\hline & & Number of Guest Rooms of Luxury Hotels & & 0.676 \\
\hline & & $\begin{array}{l}\text { Travel Time between Inner-city Areas and } \\
\text { International Airports }\end{array}$ & & 0.608 \\
\hline & \multirow[t]{5}{*}{ FF3 } & Average House Rent & & 0.388 \\
\hline & & Level of Green Coverage & & 0.374 \\
\hline & & $\begin{array}{l}\text { Number of World Heritage Sites (within } \\
100 \mathrm{~km} \text { Area) }\end{array}$ & & 0.697 \\
\hline & & $\begin{array}{l}\text { Number of Cities with International Direct } \\
\text { Flights }\end{array}$ & & 0.694 \\
\hline & & Number of Travelers of International Flights & & 0.477 \\
\hline
\end{tabular}


Table A2. Results of Principal Component Analysis (PCA) for Actor-Specific GPCI Data.

\begin{tabular}{|c|c|c|c|c|c|}
\hline Type & Actors & Factors & Variables & $\begin{array}{l}\text { KMO and } \\
\text { Bartlett's Test }\end{array}$ & $\begin{array}{l}\text { Factor } \\
\text { Loadings }\end{array}$ \\
\hline \multirow{21}{*}{ 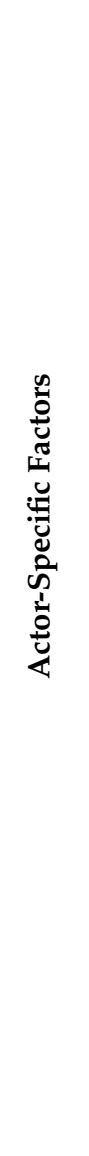 } & Artists & \multirow{4}{*}{ AF1 } & & $0,756(0,00)$ & \\
\hline & & & \multirow{4}{*}{$\begin{array}{l}\text { Cultural Stimulation } \\
\text { Accumulation of Artists } \\
\text { Accumulation of Art Markets } \\
\text { Environment for Daily Life (Ease } \\
\text { of Living) }\end{array}$} & & 0.904 \\
\hline & & & & & 0.83 \\
\hline & & & & & 0.91 \\
\hline & & AF2 & & & 0.993 \\
\hline & \multirow{8}{*}{ Visitors } & \multirow{5}{*}{ VF1 } & \multirow[b]{2}{*}{$\begin{array}{l}\text { Cultural Attractiveness and } \\
\text { Opportunities for Interaction }\end{array}$} & $0,687(0,00)$ & \\
\hline & & & & & 0.76 \\
\hline & & & Public Safety & & 0.362 \\
\hline & & & Richness in Tourist Spots & & 0.865 \\
\hline & & & $\begin{array}{l}\text { Dining (Variety of Cuisines, Prices } \\
\text { etc.) }\end{array}$ & & 0.738 \\
\hline & & \multirow{3}{*}{ VF2 } & $\begin{array}{l}\text { Mobility (Travel Time and Fares to } \\
\text { Destinations) }\end{array}$ & & 0.836 \\
\hline & & & High-class Accommodations & & 0.738 \\
\hline & & & $\begin{array}{l}\text { Shopping (Environment, Prices, } \\
\text { Attractiveness etc.) }\end{array}$ & & 0.759 \\
\hline & \multirow{8}{*}{ Residents } & \multirow{6}{*}{ RF1 } & & $0,748(0,00)$ & \\
\hline & & & $\begin{array}{l}\text { Environment for Daily Life (Ease } \\
\text { of Living) }\end{array}$ & & 0.748 \\
\hline & & & $\begin{array}{l}\text { Work Environment (Income and } \\
\text { Employment Opportunities) }\end{array}$ & & 0.461 \\
\hline & & & Educational Environment & & 0.837 \\
\hline & & & Leisure Activities & & 0.672 \\
\hline & & & Public Safety & & 0.694 \\
\hline & & RF2 & Quality of Medical Treatment & & 0.611 \\
\hline & & RF3 & $\begin{array}{l}\text { Environment to Purchase Goods } \\
\text { (Prices and Easiness) }\end{array}$ & & 0.032 \\
\hline
\end{tabular}


Table A3. Language Diversity Score (WADI) (Fractionalization Index for 40 Global Cities).

\begin{tabular}{cc}
\hline City & Diversity Index \\
\hline Amsterdam & 0.630990228 \\
Bangkok & 0.580275283 \\
Barcelona & 0.739649775 \\
Beijing & 0.568273281 \\
Berlin & 0.713886342 \\
Boston & 0.178647939 \\
Brussels & 0.767415173 \\
Cairo & 0.607552989 \\
Chicago & 0.262554543 \\
Copenhagen & 0.577731831 \\
Frankfurt & 0.764760707 \\
Fukuoka & 0.507820971 \\
Geneva & 0.675134626 \\
Hong Kong & 0.44619284 \\
Istanbul & 0.574840544 \\
Kuala Lumpur & 0.435454665 \\
London & 0.695088697 \\
Los Angeles & 0.499130667 \\
Madrid & 0.734850166 \\
Mexico City & 0.581510196 \\
Milan & 0.741487602 \\
Moscow & 0.636373875 \\
Mumbai & 0.044690735 \\
New York & 0.561990642 \\
Osaka & 0.686164572 \\
Paris & 0.700370375 \\
San Francisco & 0.416990364 \\
Sao Paulo & 0.09045615 \\
Seoul & 0.628025993 \\
Shanghai & 0.388350389 \\
Singapore & 0.302669248 \\
Stockholm & 0.660920719 \\
Sydney & 0.229742011 \\
Taipei & 0.619280373 \\
Tokyo & 0.672977925 \\
Toronto & 0.255566872 \\
Vancouver & 0.211170354 \\
Vienna & 0.735049482 \\
Washington & 0.252953000 \\
Zurich & 0.643879363 \\
\hline & \\
\hline &
\end{tabular}

Table A4. Complementary Regression Model Results based on Panel Data for the GPCI Data Base (2012-2015).

\begin{tabular}{cccc}
\hline & Estimated Coefficients & Std. Error & Sig. \\
\hline FF1 & 0,276 & 0,090 & 0,002 \\
FF3 & 0,250 & 0,064 & 0,000 \\
AF2 & 0,359 & 0,118 & 0,003 \\
VF2 & 0,417 & 0,088 & 0,000 \\
RF2 & $-0,249$ & 0,084 & 0,004 \\
Intercept & 8,118 & 0,053 & 0,000 \\
\hline Observations & 40 & & \\
$R^{2}$ & 0,48 & & \\
Method & OLS & \\
\hline
\end{tabular}




\section{References}

1. Giaoutzi, M.; Nijkamp, P. Tourism and Regional Development; Ashgate Publishing: Furnham, Surrey, UK, 2006.

2. Romão, J. Tourism, Territory and Sustainable Development; Springer: Singapore, 2018.

3. Matias, A.; Nijkamp, P.; Sarmento, M. Tourism Economics: Impact Analysis; Springer: Berlin, Germany, 2011.

4. Kastenholz, E. Management of Demand' as a Tool in Sustainable Tourist Destination Development. J. Sustain. Tour. 2004, 12, 388-408. [CrossRef]

5. Matias, A.; Nijkamp, P.; Romão, J. Impact Assessment in Tourism Economics; Springer: Berlin, Germany, 2016.

6. Silberberg, T. Cultural Tourism and Business Opportunities for Museums and Heritage Sites. Tour. Manag. 1995, 16, 361-365. [CrossRef]

7. Kourtit, K.; Nijkamp, P. Impact of Cultural "Ambiance" on the Spatial Distribution of Creative Professions A Modeling Study on the Netherlands. Int. Reg. Sci. Rev. 2016, 41, 103-128. [CrossRef]

8. Fusco Girard, L.; Nijkamp, P. Cultural Tourism and Sustainable Local Development; Ashgate Publishing: Furnham, Surrey, UK, 2009.

9. Yu, K. Cultural Variations in Landscape Preference: Comparisons among Chinese Sub-Groups and Western Design Experts. Landsc. Urban. Plan. 1995, 32, 107-126. [CrossRef]

10. Chen, C.F.; Chen, F.S. Experience Quality, Perceived Value, Satisfaction and Behavioral Intentions for Heritage Tourists. Tour. Manag. 2010, 31, 29-35. [CrossRef]

11. Noonan, D. Evaluating the Impact of Heritage Policies: Landmark Preservation in Chicago. Cultural Tourism and Sustainable Local Development; Fusco Girard, L., Nijkamp, P., Eds.; Ashgate Publishing: Furnham, Surrey, UK, 2009; pp. 289-314.

12. Stebbins, R.A. Cultural Tourism as Serious Leisure. Ann. Tour. Res. 1996, 23, 948-950. [CrossRef]

13. Stylianou-Lambert, T. Gazing from Home: Cultural Tourism and Art Museums. Ann. Tour. Res. 2011, 38, 403-421. [CrossRef]

14. Wang, Y.; Chan, S.; Ngas, G. Applicability of Demographic Recommender System to Tourist Attractions. In Proceedings of the International Conference on Web Intelligence and Intelligent Agent Technology (2012 IEEEE/WIC/ACM), Macau, China, 4-7 December 2012.

15. Poria, Y.; Butler, R.; Airey, D. The Core of Heritage Tourism. Ann. Tour. Res. 2003, 30, 238-254. [CrossRef]

16. Manzanek, J. Managing the Heterogeneity of City Tourists. In Analysing International City Tourism; Manzanek, J., Wöber, K., Eds.; Springler: Berlin, Germany, 2010; pp. 81-94.

17. Romão, J.; Neuts, B.; Nijkamp, P.; van Leeuwen, E.S. Culture, Product Differentiation and Market Segmentation: A Structural Analysis of the Motivation and Satisfaction of Tourists in Amsterdam. Tour. Econ. 2015, 21, 455-474. [CrossRef]

18. Clark, D.; Kahn, J. The Social Benefits of Urban Cultural Amenities. J. Reg. Sci. 1988, 28, 363-377. [CrossRef]

19. Moro, M.; Lyons, S.; Mayor, K.; Tol, R.S.J. Does the Housing Market Reflect Cultural Heritage? A Case Study of Greater Dublin. Environ. Plan. A 2013, 45, 2884-2903. [CrossRef]

20. Nijkamp, P. Economic Valuation of Cultural Heritage. In The Economics of Uniqueness; Licciardi, G., Amirtahmasebi, G., Eds.; The World Bank: Washington, DC, USA, 2012; pp. 75-106.

21. Sacco, P.; Ferilli, G.; Blessi, G.T.; Sacco, P.; Ferilli, G.; Blessi, G.T. Understanding Culture-Led Local Development: A Critique of Alternative Theoretical Explanations. Urban. Stud. 2014, 51, $2806-2821$. [CrossRef]

22. Sheppard, S. Museums in the Neighborhood: The Local Economic Impact of Museums', Handbook of Economic Geography and Industry Studies; Giarattani, F., Hewings, G., McCann, P., Eds.; Edward Elgar: Cheltenham, UK, 2013; Chapter 8.

23. Throsby, D. Tourism, Heritage and Cultural Sustainability. In Cultural Tourism and Sustainable Local Development; Fusco Girard, L., Nijkamp, P., Eds.; Ashgate Publishing: Furnham, Surrey, UK, 2009; pp. 13-30.

24. Wall, G. Tourism and Development: Towards Sustainable Outcomes, Cultural Tourism and Sustainable Local Development; Fusco Girard, L., Nijkamp, P., Eds.; Ashgate Publishing: Furnham, Surrey, UK, 2009; pp. 31-46.

25. Arribas-Bel, D.; Kourtit, K.; Nijkamp, P. The Sociocultural Sources of Urban Buzz. Environ. Plan. C 2016, 34, 188-204. [CrossRef]

26. Guzmán, P.C.; Pereira Roders, A.R.; Colenbrander, B.J.F. Measuring Links between Cultural Heritage Management and Sustainable Urban Development: An Overview of Global Monitoring Tools. Cities 2017, 60, 192-201. [CrossRef] 
27. Santagata, W. Cultural Districts, Property Rights and Sustainable Economic Growth. Int. J. Urban. Reg. Res. 2002, 26, 9-23. [CrossRef]

28. Zhang, Z.; Ye, Q.; Law, R. Development of Hotel Room Price. Int. J. Contemp. Hosp. Manag. 2011, 23, 972-981. [CrossRef]

29. Zerva, K.; Nijkamp, P.; Kourtit, K. Tourism and Voyeurism in Heterotopia's: The Role of Perception and Information in the Behaviour of Visitors to Amsterdam. In Impact Assessment in Tourism Economics; Matias, A., Nijkamp, P., Romao, J., Eds.; Springer: Cham, Switzerland, 2016; pp. 247-273.

30. Andriotis, K. Heterotopic Erotic Oasis: The Public Nude Beach Experience. Ann. Tourism Res. 2010, 37, 1076-1096. [CrossRef]

31. Garretsen, J.; Marlet, G. Amenities and the Attraction of Dutch Cities. Reg. Stud. 2017, 51, 724-736. [CrossRef]

32. Kourtit, K. Super-Proximity and Spatial Development. J. Reg. Res. 2016, 36, 215-231.

33. Mocann, D.; Baronchelli, A.; Perra, N.; Goncalves, B.; Zheng, Q.; Vespignani, A. The Twitter of Babel. PLoS ONE 2013, 8, 61981.

34. Owens, T. TripAdvisor Rates Einstein. Int. J. Web Based Commun. 2012, 8, 40-56. [CrossRef]

35. Sfandla, C.; Björk, P. Tourism Experience Network: Co-creation of Experiences in Interactive Processes. Int. J. Tour. Res. 2013, 15, 495-506. [CrossRef]

36. Mansson, M. Mediatized Tourism. Ann. Tour. Res. 2011, 38, 1634-1652. [CrossRef]

37. Sigala, M.; Mich, L.; Murphy, J. Information and Communication Technologies in Tourism; Springer: Heidelberg, Germany, 2008.

38. Ferreri, M.; Sanyal, R. Platform Economies and Urban Planning: Airbnb and Regulated Deregulation in London. Reg. Stud. 2018, 55, 3353-3368. [CrossRef]

39. Law, R. Internet and Tourism. J. Travel Tour. Mark. 2006, 20, 75-77. [CrossRef]

40. Ramon Saura, J.; Reyes-Menendez, A.; Alvarez-Alonso, C. Do Online Comments Affect Environmental Management? Identifying Factors Related to Environmental Management and Sustainability of Hotels. Sustainability 2018, 10, 3016. [CrossRef]

41. Carter, D. Urban Regeneration, Digital Development Strategies, and the Knowledge Economy. J. Knowl. Econ. 2013, 4, 169-189. [CrossRef]

42. Deakin, M. Smart Cities; Routledge: London, UK, 2013.

43. Caragliu, A.; Del Bo, C.; Nijkamp, P. Smart Cities in Europe. J. Urban. Technol. 2011, 18, 65-82. [CrossRef]

44. Evans-Cowley, J.; Hollander, J. The New Generation of Public Participation, Internet-based Participation Tools. Plan. Pract. Res. 2010, 25, 397-408. [CrossRef]

45. Kumar, T.M.V. E-Governance for Smart Cities; Springer: Singapore, 2015.

46. Romão, J.; Neuts, B.; Nijkamp, P.; van Leeuwen, E.S. Tourist Loyalty and e-Services: A Comparison of Behavioural Impacts in Leipzig and Amsterdam. J. Urban. Technol. 2015, 22, 85-101. [CrossRef]

47. Norris, D.F.; Reddick, C.G. Local E-Government in the United States. Public Adm. Rev. 2013, 73, $165-175$. [CrossRef]

48. Yigitcanlar, T.; Lee, S.H. Korean Ubiquitous Eco-City. Technol. Forecast. Soc. Chang. 2014, 89, 100-114. [CrossRef]

49. Boes, K.; Buhalis, D.; Inversini, A. Smart Tourism Destinations: Ecosystems for Tourism Destination Competitiveness. Int. J. Tour. Cities 2016, 2, 108-124. [CrossRef]

50. Nijkamp, P.; Kourtit, K. Smart Cities in Smart Space. It. J. Reg. Sci. 2016.

51. Moreno-Izquierdo, L.; Egorova, G.; Pereto-Rovira, A.; Mas-Fernando, A. Exploring the Use of Artificial Intelligence in Price Maximization in the Tourism Sector: Its Application in the Case of Airbnb in the Valencian Communit. J. Reg. Res. 2018, 42, 113-128.

52. Marine-Roig, E. Measuring Destination Image through Travel Reviews in Search Engines. Sustainability 2017, 9, 1425. [CrossRef]

53. Ahas, R.; Aasa, A.; Mark, U.; Kull, T. Seasonal Tourism Spaces in Estonia: Case Study with Mobile Positioning Data. Tour. Manag. 2006, 28, 848-910. [CrossRef]

54. Lee, C.F.; Huang, F.H.; Yeh, H.R. Developing an Evaluation Model for Destination Attractiveness: Sustainable Forest Recreation Tourism in Taiwan. J. Sustain. Tour. 2010, 18, 811-828. [CrossRef]

55. Girard, F.; Calabrise, F.; Dal Fiore, F.; Ratti, C. Digital Footprinting: Uncovering Tourists with User-Generated Content. IEEE Pervasive. Comput. 2008, 7, 36-43. [CrossRef] 
56. Hawelka, B.; Sitko, I.; Beinat, E.; Sobolovsky SKazakopanles, P.; Ratti, C. Geo-Located Twitter as Proxy for Global Mobility Patterns. Cartogr. Geogr. Inf. Sci. 2014, 41, 260-271. [CrossRef]

57. Dickinson, J.E.; Ghali, K.; Cherrett, T.; Speed, C.; Davies, N.; Norgats, S. Tourism and the Smartphone App. Curr. Issues Tour. 2014, 17, 84-101. [CrossRef]

58. Meng, B.; Kim, M.-H.; Hwang, Y.-H. Users and Non-Users of Smartphones for Travel. Asia Pac. J. Tour. Res. 2015, 20, 1094-1110. [CrossRef]

59. Riganti, P. From Cultural Tourism to Cultural E-Tourism. Cultural Tourism and Sustainable Local Development; Fusco Girard, L., Nijkamp, P., Eds.; Ashgate Publishing: Furnham, Surrey, UK, 2009; pp. 263-288.

60. Tussyadiah, I.P.; Zack, F.J. The Role of Geo-based Technology in Place Experience. Ann. Tour. Res. 2012, 39, 780-800. [CrossRef]

61. Wang, D.; Park, S.; Fesenmaier, D.R. The Role of Smartphones in Mediating the Touristic Experience. J. Travel Res. 2012, 51, 371-387. [CrossRef]

62. Wang, D.; Ziang, Z.; Fesenmaier, D.R. Smartphone Use in Everyday Life and Travel. J. Travel Res. 2016, 58, 52-63. [CrossRef]

63. Wang, D.; Niu, Y.; Lu, L.; Qian, J. Tourism Spatial Organization of Historical Streets-A Postmodern Perspective: The Examples of Pingjiang Road and Shantang Street, Suzhou, China. Tour. Manag. 2015, 48, 370-385. [CrossRef]

64. Mitchell, L.; Frank, M.R.; Harris, K.D.; Dodds, P.S.; Danforth, C.M. The Geography of Happiness. PLoS ONE 2013, 8, 64417.

65. Jeacle, I.; Carter, C. In TripAdvisor We Trust. Acc. Organ. Soc. 2011, 36, 293-309. [CrossRef]

66. Tuominen, P. The Influence of TripAdvisor Consumer-Generated Travel Reviews on Hotel Performance; Working Paper; Business School, University of Hertforshire: Hertforshire, UK, 2011.

67. Cunningham, P.; Smyth, B.; Wu, G.; Greene, D. Does TripAdvisor Make Hotels Better; Technical Report UCD-CSI-2010-16; University College Dublin: Dublin, Ireland, 2010.

68. Bulchand-Gidumal, J.; Melian-Gonzalez, S.; Lopez-Valcarcel, B.G. A Social Media Analysis of the Contribution of Destinations to Client Satisfaction with Hotels. Int. J. Hospitality Manag. 2013, 35, 44-47. [CrossRef]

69. Amaral, F.; Tiago, T.; Tiago, F. User-Generated Content: Tourists' Profiles on TripAdvisor. Int. J. Strateg. Innov. Mark. 2014, 1, 137-147. [CrossRef]

70. Ayeh, J.K.; Au, N.; Law, R. Do We Believe in TripAdvisor? J. Travel Res. 2013, 20, 1-16.

71. Filieri, R.; Alguezani, S.; McLeavy, F. Why Do Travellers Trust TripAdvisor? Tour. Manag. 2015, 541, $174-185$. [CrossRef]

72. O'Connor, P. Managing a Hotel's Image on TripAdvisor. J. Hospitality Mark. Manag. 2010, 19, 754-772. [CrossRef]

73. Lei, S.; Law, R. Content Analysis of TripAdvisor Reviews on Restaurants. J. Tour. 2015, 16, 17-28.

74. Kladou, S.; Mavragani, E. Assessing Destination Image. J. Destin. Mark. Manag. 2015, 4, 187-193.

75. Sigala, M. WEB 2.0, Social Marketing Strategies and Distribution Channels for City Destinations, Information Communication Technologies and City Marketing; Gascó-Hernandez, M., Torres-Coronas, T., Eds.; IGI Global: Washington, DC, USA, 2009; pp. 1280-1304.

76. Briggs, S.; Sutherland, J.; Drummond, S. Are Hotels Serving Quality? Tour. Manag. 2007, 28, $1006-1009$. [CrossRef]

77. Van der Zee, E.; Bertocchi, D.; Vanneste, D. Distribution of tourists within urban heritage destinations: A hot spot/cold spot analysis of TripAdvisor data as support for destination management. Tourism 2018, 21, 1-22. [CrossRef]

78. Van der Zee, E.; Bertocchi, D. Finding patterns in urban tourist behaviour: A social network analysis approach based on TripAdvisor reviews. Inf. Technol. Tour. 2018, 20, 153-180. [CrossRef]

79. Franzoni, S.; Bonera, M. How DMO Can Measure the Experiences of a Large Territory. Sustainability 2019, 11, 492. [CrossRef]

80. Cortese, F.; D’Ambrosio, I.; Petracca, M. A Possible Synergy between Culture and Religion for the Sustainability of Tourism of Pompeii. Sustainability 2019, 11, 2231. [CrossRef]

81. Alesina, A.; Harnoss, J.; Rapoport, J. Birthplace Diversity and Economic Prosperity; NBER Working Paper no. 18699; National Bureau of Economic Research: Cambridge, MA, USA, 2013.

82. Desmet, K.; Weber, S.; Ortuno-Ortin, I. Linguistic Diversity and Redistribution. J. Eur. Econ. Assoc. 2009, 7, 1291-1381. [CrossRef] 
83. Nijkamp, P.; Poot, J.; Bakens, J. The Economics of Cultural Diversity; Edward Elgar: Cheltenham, UK, 2015.

84. Swensen, G. Integration of Historic Fabric in New Urban Development-A Norwegian Case-Study. Landsc. Urban. Plan. 2012, 107, 380-388. [CrossRef]

85. Goeldner, C.; Brent Ritchie, J. Tourism, Principles, Practices, Philosophies; John Wiley: Hoboken, NJ, USA, 2012.

(C) 2019 by the authors. Licensee MDPI, Basel, Switzerland. This article is an open access article distributed under the terms and conditions of the Creative Commons Attribution (CC BY) license (http://creativecommons.org/licenses/by/4.0/). 